\title{
Genotype and phenotype landscape of MEN2 in 554 medullary thyroid cancer patients: the BrasMEN study
}

Rui M B Maciel ${ }^{1, *}$, Cleber P Camacho ${ }^{1, *}$, Lígia V M Assumpção², Natassia E Bufalo², André L Carvalho3, Gisah A de Carvalho ${ }^{4}$, Luciana A Castroneves 5 ,6, Francisco M de Castro Jr ${ }^{7}$, Lucieli Ceolin ${ }^{8}$, Janete M Cerutti ${ }^{1}$, Rossana Corbo ${ }^{9}$, Tânia M B L Ferraz ${ }^{10}$, Carla V Ferreira ${ }^{8}$, M Inez C França ${ }^{11,12}$, Henrique C R Galvão ${ }^{3}$, Fausto Germano-Neto ${ }^{1}$, Hans Graf ${ }^{4}$, Alexander A L Jorge ${ }^{5}$, Ilda S Kunii', Márcio W Lauria ${ }^{13}$, Vera L G Leal ${ }^{14}$, Susan C Lindsey', Delmar M Lourenço Jr5,6, Léa M Z Maciel ${ }^{15}$, Patrícia K R Magalhães ${ }^{15}$, João R M Martins ${ }^{1}$, M Cecília Martins-Costa ${ }^{1,10,16}$, Gláucia M F S Mazeto ${ }^{17}$, Anelise I Impellizzeri' ${ }^{13}$, Célia R Nogueira ${ }^{17}$, Edenir I Palmero ${ }^{3,18}$, Cencita H C N Pessoa ${ }^{9}$, Bibiana Prada ${ }^{17}$, Débora R Siqueira ${ }^{8}$, Maria Sharmila A Sousa ${ }^{1,19}$, Rodrigo A Toledo ${ }^{5,20}$, Flávia O F Valente ${ }^{1}$, Fernanda Vaismann', Laura S Ward ${ }^{2}$, Shana S Weber ${ }^{8}$, Rita V Weiss ${ }^{14}$, Ji H Yang', Magnus R Dias-da-Silva', Ana O Hoff5,6, Sergio P A Toledo ${ }^{1,5}$ and Ana L Maia ${ }^{8}$

${ }^{1}$ Escola Paulista de Medicina, Universidade Federal de São Paulo, São Paulo, São Paulo, Brazil

${ }^{2}$ Faculdade de Ciências Médicas, Universidade de Campinas, Campinas, São Paulo, Brazil

${ }^{3}$ Hospital de Câncer de Barretos, Barretos, São Paulo, Brazil

${ }^{4}$ Faculdade de Medicina, Universidade Federal do Paraná, Curitiba, Paraná, Brazil

${ }^{5}$ Faculdade de Medicina da Universidade de São Paulo, São Paulo, São Paulo, Brazil

IInstituto do Câncer do Estado de São Paulo, São Paulo, São Paulo, Brazil

${ }^{7}$ Universidade Federal do Ceará, Fortaleza, Ceará, Brazil

${ }^{8}$ Hospital de Clínicas de Porto Alegre and Faculdade de Medicina da Universidade Federal do Rio Grande do Sul, Porto Alegre, Rio Grande do Sul, Brazil ${ }^{9}$ Instituto Nacional do Câncer, Rio de Janeiro, Rio de Janeiro, Brazil

${ }^{10}$ Hospital Geral de Fortaleza, Fortaleza, Ceará, Brazil

${ }^{11}$ Universidade Federal do Espírito Santo, Vitória, Espírito Santo, Brazil

${ }^{12}$ Hospital Santa Rita de Cássia, Vitória, Espírito Santo, Brazil

${ }^{13}$ Faculdade de Medicina da Universidade Federal de Minas Gerais, Belo Horizonte, Minas Gerais, Brazil

${ }^{14}$ Instituto Estadual de Diabetes e Endocrinologia, Rio de Janeiro, Rio de Janeiro, Brazil

${ }^{15}$ Faculdade de Medicina de Ribeirão Preto, Universidade de São Paulo, Ribeirão Preto, São Paulo, Brazil

${ }^{16}$ Universidade de Fortaleza, Fortaleza, Ceará, Brazil

${ }^{17}$ Faculdade de Medicina de Botucatu, Universidade Estadual Paulista, Botucatu, São Paulo, Brazil

${ }^{18}$ Faculdade de Ciências da Saúde de Barretos Dr. Paulo Prata, Barretos, São Paulo, Brazil

${ }^{19}$ Escola Fiocruz de Governo, Fundação Oswaldo Cruz and Ministério da Saúde, Brasília, Distrito Federal, Brazil

${ }^{20}$ Vall d'Hebron Institute of Oncology (VHIO), CIBERONC, Barcelona, Spain

Correspondence should be addressed to R M B Maciel or S C Lindsey: rui.maciel@unifesp.br or sclindsey@unifesp.br

*(R M B Maciel and C P Camacho contributed equally to this work)

\begin{abstract}
Multiple endocrine neoplasia type 2 (MEN2) is an autosomal dominant genetic disease caused by RET gene germline mutations that is characterized by medullary thyroid carcinoma (MTC) associated with other endocrine tumors. Several reports have demonstrated that the RET mutation profile may vary according to the geographical area. In this study, we collected clinical and molecular data from 554 patients with surgically confirmed MTC from 176 families with MEN2 in 18 different Brazilian centers to compare the type and prevalence of RET mutations with those from other countries. The most frequent mutations, classified by the number of families affected, occur in codon 634, exon 11 (76 families), followed by codon 918, exon 16 (34 families: 26 with M918T and 8 with M918V) and codon 804, exon 14 (22 families: 15 with V804M and 7 with V804L). When compared with other major published series from Europe, there are several similarities
\end{abstract} Key Words

- RET

- Brazil

- multiple endocrine neoplasia

- medullary thyroid carcinoma

- pheochromocytoma 
and some differences. While the mutations in codons C618, C620, C630, E768 and S891 present a similar prevalence, some mutations have a lower prevalence in Brazil, and others are found mainly in Brazil (G533C and M918V). These results reflect the singular proportion of European, Amerindian and African ancestries in the Brazilian mosaic genome.

\section{Introduction}

Multiple endocrine neoplasia type 2 (MEN2) is an autosomal dominant genetic syndrome characterized by the association of endocrine tumors. MEN2 is classified into two subtypes, MEN type 2A (MEN2A; OMIM \#171400) and MEN type 2B (MEN2B; OMIM \#162300), according to its clinical manifestations, characterized by a high penetrance of medullary thyroid carcinoma (MTC), and to a lesser degree, pheochromocytoma (PHEO) and primary hyperparathyroidism (PHPT) $(1,2,3,4)$.

Despite being traditionally considered a rare disease, the earlier diagnosis and the discovery of asymptomatic carriers of MEN2 have increased its prevalence, from approximately 1 case per 200,000 or 500,000 inhabitants to possibly 1:80,000 inhabitants (5). As an example, in Norway, a country where epidemiological data from the entire population have recently been published, the incidence of patients with RET mutations associated with MEN2 was 1:66,438 live births, while the prevalence of MEN2 was $1: 79,462$ (6).

MEN2A and MEN2B are caused by germline mutations of the RET gene $(7,8,9,10,11)$. The demonstration that RET mutations are associated with the MEN2 phenotype have altered not only the diagnosis but also the treatment of these patients, as they have enabled the identification of asymptomatic carriers who could be treated prophylactically. Moreover, a correlation between disease phenotype and the codon of the affected RET mutation was acknowledged $(1,2,12)$. Since MTC occurs in $95 \%$ of MEN2A patients and RET mutations in different codons result in variable disease manifestations, investigations have been carried out to identify predictors for the optimal timing and extent of prophylactic thyroid surgery (13, 14). Guidelines and treatment recommendations issued by the American Thyroid Association (ATA) and other associations were based on these studies $(2,3,12,15,16)$.

A number of reports that included a large number of affected patients have demonstrated that the RET mutation profile may vary according to geographical area $(5,6,17$, $18,19,20,21,22,23)$. Brazil has a territory of continental size, with an area of 8.5 million square kilometers and a population of more than 209 million inhabitants, with a singular proportion of European, Amerindian and
African ancestries in its mosaic genome $(24,25)$. Indeed, recent ethnographic fieldwork and haplotype analysis traced founder mutations from Brazil back to the Iberian Peninsula and Greece $(20,22)$. Of note, an international consortium (26) found that the penetrance of PHEO in MEN2 patients carrying RET mutations on exons 10 and 11 is lower in countries from South America (including many patients from Brazil) than in Europe and proposed that other genetic or environmental modifiers could explain this difference. By the same token, we have shown a lower penetrance of PHEO in patients carrying the RET G533C mutation (exon 8) in Brazil than in Greece (27).

Considering the findings above, this study aimed to collect RET gene genotyping data from as many Brazilian families with MEN2 as possible, to analyze the distribution and frequency of RET mutations, and to compare the type and prevalence of RET mutations with those of other countries.

\section{Patients and methods}

The subjects of this study were 2201 individuals from 176 kindreds who underwent RET molecular screening in 18 reference centers in Brazil. Since RET screening was established, each time a new patient with MTC was diagnosed, he or she underwent RET genotyping and a common protocol was followed by all centers following available guidelines $(2,3,12,15,16)$. The following centers participated in this study: Universidade Federal de São Paulo (UNIFESP), Faculdade de Medicina, Universidade de São Paulo (FMUSP), and Instituto do Câncer do Estado de São Paulo (ICESP) in São Paulo; Universidade Federal do Rio Grande do Sul (UFRGS) in Porto Alegre; Universidade de Fortaleza (UNIFOR), Universidade Federal do Ceará (UFC), and Hospital Geral de Fortaleza (HGF) in Fortaleza; Instituto Nacional do Câncer (INCA) and Instituto Estadual de Diabetes e Endocrinologia (IEDE) in Rio de Janeiro; Universidade Federal do Espirito Santo (UFES) and Hospital Santa Rita de Cássia (HSR) in Vitória; Hospital de Câncer de Barretos (HCB) and Faculdade de Ciências da Saúde de Barretos Dr. Paulo Prata (FACISB) in Barretos;

This work is licensed under a Creative Commons Attribution-NonCommercial-NoDerivatives 4.0 Internationab ticense.ifica.com at 04/26/2023 11:52:06AM 
Universidade Estadual Paulista (UNESP) in Botucatu; Universidade de Campinas (UNICAMP) in Campinas; Faculdade de Medicina de Ribeirão Preto, Universidade de São Paulo (FMRP-USP) in Ribeirão Preto; Universidade Federal de Minas Gerais (UFMG) in Belo Horizonte and Universidade Federal do Paraná (UFPR) in Curitiba.

For the phenotypic classification, each center replied questionnaires that recorded individual clinical evaluations of patients and families according to the criteria proposed by the American Thyroid Association (ATA) (2) and the Brazilian Society of Endocrinology and Metabolism (16); additionally, all patients were staged according to the TNM (tumor, lymph nodes, metastases) classification system of the American Joint Committee on Cancer (AJCC)/TNM (28). After receiving the completed questionnaires, we organized the information from the worksheets and compiled the data in a unique document.

Informed consent from patients and approval by research ethics committees from all centers were obtained. All subjects received pre- and post-test genetic counseling. The study was approved by the Institutional Review Board and Ethics Committee of the Universidade Federal de São Paulo (CEP 1749/06).

When RET screening became a routine test in the Laboratory of Molecular and Translational Endocrinology of the Universidade Federal de São Paulo, in the beginning of 2002, all index cases and, when appropriate, their firstdegree relatives were screened for pathogenic mutations and also a prospective evaluation began. We performed sequencing of the hotspot exons and, when necessary, of the entire coding region of RET using DNA extracted from whole blood samples from patients from UNIFESP, UNIFOR, UFC, HGF, INCA, IEDE, UFES, UNICAMP, IEDE, UFMG and UFPR (29). Patients from UFRGS, FMUSP, ICESP, HCB, UNESP and FMRP-USP were genotyped following similar protocols in their respective laboratories using previously published techniques $(30,31,32)$. When a mutation was identified in the index case, members of the family were screened accordingly using the criteria for gene autosomal dominant transmission and only at the involved exon. The data collected for each individual included the clinical characteristics of family members (association with other endocrine neoplasias), the RET mutation, presence of $\mathrm{PHEO}$ or primary hyperparathyroidism (PHPT) and information on other features noted, such as HSCR or CLA.

For the statistical analysis of the data, we first calculated the averages, medians, means, maximum and minimum values; we used the percentages considering the total number of cases for a specific phenotype or genotype.
We analyzed the categorical variables by means of the chisquare test with Fisher's correction when appropriate; for continuous variables, we used the Kruskal-Wallis test. We used 'IBM SPSS Statistics for Windows, version 25' (IBM Corp.). We considered $P<0.05$ as statistically significant.

\section{Results}

Table 1 shows the clinical and molecular results from MEN2 patients from 18 different Brazilian centers; overall, 554 patients with surgically confirmed MTC from 176 families were identified, indicating 30 different germline mutations in 12 codons of 7 exons $(8,10,11,13,14,15$, 16) of the RET gene.

In our series, we were able to determine the germline mutation for all patients with MEN2, which is different from other reports that present a small proportion of patients with negative RET genotyping. The most frequent mutations, classified by the number of families affected, occurred in codon 634, exon 11 (76 families), followed by codon 918, exon 16 (34 families: 26 with M918T and 8 with M918V) and codon 804, exon 14 (20 families: 15 with V804M and 7 with V804L).

When mutations were analyzed by the absolute number of patients with an established diagnosis of MTC after surgery, the most frequently found mutations were in codons 634 (262 patients, 47.3\%), 533 (59 patients, 10.6\%), 620 (56 patients, 10.1\%) and 918 (53 patients, 9.6\%).

Regarding the 262 patients affected by a mutation at codon 634, 166 were C634Y (63.4\%), 74 were C634R (28.2\%), 10 were C634W (3.8\%), 8 were C634G (3.1\%), 3 were C634S (1.1\%) and 1 was a C634F mutation $(0.4 \%)$. In 47 of these cases, we observed that the Y791F variant co-occurred with the strong C634 mutation (C634/Y791F), as previously reported (33, 34, 35).

After MTC, the most frequently found association among patients with MEN2 was PHEO (21.3\% of all patients). The codon-specific penetrance of PHEO showed that the penetrance was highest for patients with a C634 mutation (79.2\% of all patients with PHEO and $36.3 \%$ of all individuals with a mutation in codon 634), followed by codon M918T (10\% of all patients with PHEO and $37.5 \%$ of all with a mutation in codon M918T) and by codon C620 (5.8\% of all patients with PHEO and 12.5\% of all with a mutation in codon 620). PHPT and CLA were mainly described in patients with a mutation at codon 634, with 46 and 42 cases, respectively. On the other hand, cases of HRSC were noted only in mutation carriers at codon 620 .

This work is licensed under a Creative Commons Attribution-NonCommercial-NoDerivatives 4.0 Internationab kicense.ifica, com at $04 / 26 / 202311: 52: 06 A M$ 


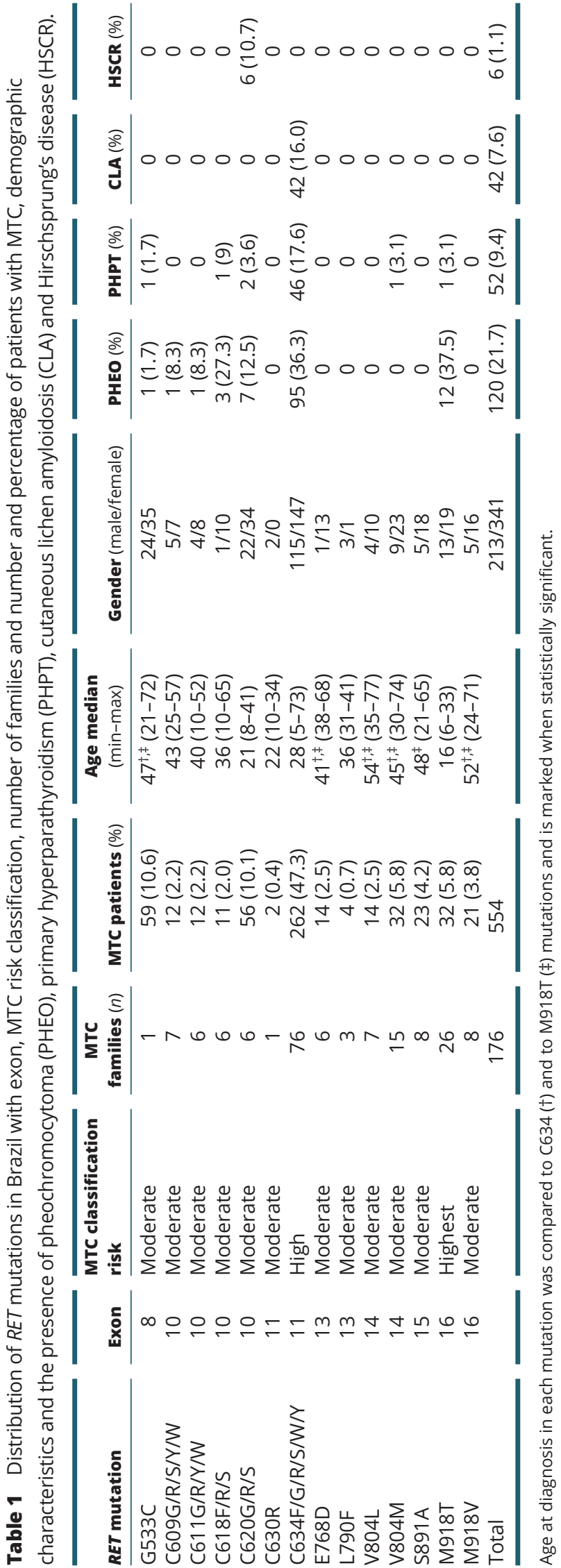

https://ec.bioscientifica.com https://doi.org/10.1530/EC-18-0506 (c) 2019 The authors Published by Bioscientifica Ltd
There was a predominance of women in our cohort (61.5\%). For age, the youngest patient diagnosed with MTC was 5 years old and had a C634 mutation. For the M918T mutation, which is associated with the most aggressive form of MEN2, the youngest age at diagnosis was 6 years. Interestingly, we observed children carrying mutations in codons 611, 618, 620 (exon 10) and 630 (exon 11), which are considered of moderate risk in the new ATA classification system, who were affected by MTC as early as 8 and 10 years old. On the other hand, the patients affected later carried mutations in codons V804L and V804M.

Table 2 shows the pathological characteristics of each mutation observed in our cohort. Higher proportions of non-T1 tumors were seen in the C618 (80\%), V804L (71.4\% of 7 cases) and M918T (65.4\%) cases. In addition, lymph node metastases (N1) at diagnosis were more frequently seen in patients with M918T (78.6\%), C620 (66.7\%) and M918V (60\%) mutations. Unfortunately, several patients presented with distant metastases at the time of diagnosis, including 39.3\% of those with a mutation at the M918T codon, $23.8 \%$ of those with mutations at codon C620 and $12.2 \%$ of those with mutations at the C634 codon.

Table 3 compares our results $(n=176$ families, 554 patients) with some of the largest published series in the literature, from Italy ( $n=245$ families), Germany ( $n=191$ families) and France ( $n=444$ families) $(5,18,36)$, excluding patients with RET variant Y791F, currently considered a non-pathogenic variant (34). Although there were several similarities, we found several differences. While mutations in codons C618, C620, C630, E768 and $\mathrm{S} 891$ presented a similar prevalence, mutations in codon L790 were more frequent in Germany and France $(P<0.01)$, as was the V804 mutation in Italy and France $(P<0.05)$. As for the C634 mutation, the prevalence in Brazil (43.2\%) was higher than that in Italy and France $(P<0.05)$. The highest risk mutation, M918T, was more frequent in our study than in Italy $(P<0.05)$ and France $(P<0.01)$. The G533C and M918V mutations were found mainly in Brazil.

\section{Discussion}

Molecular epidemiology evaluates the contribution of genetic risk factors in the etiology, geographic distribution and prevention of a particular disease. Few areas of medicine have been so clearly affected by genetic diagnosis and management as MEN2, in which an activating mutation of the RET gene results in the development of

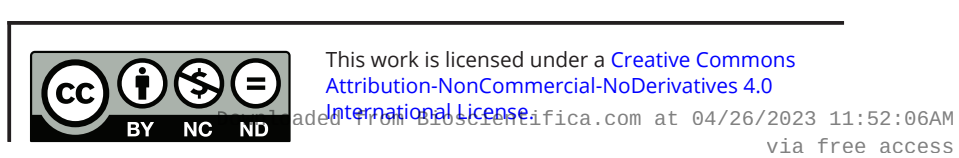




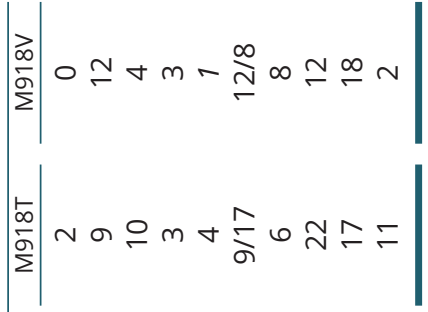

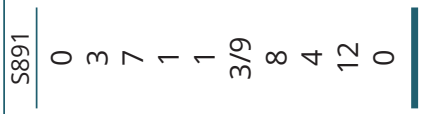

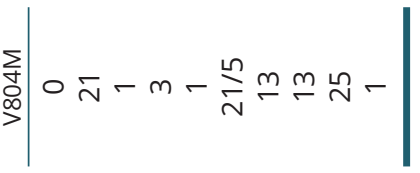

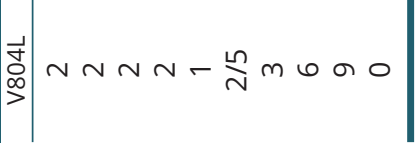

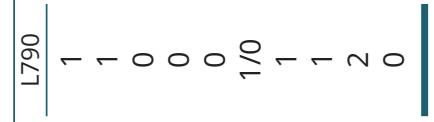

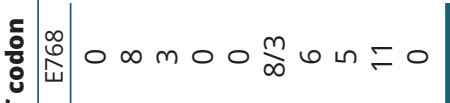

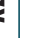

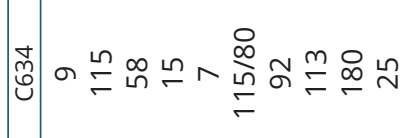

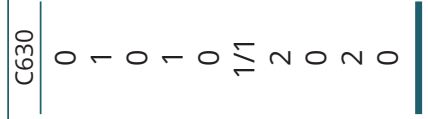

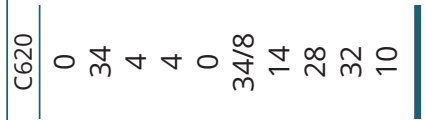

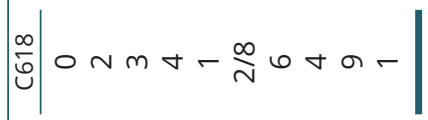

$$
\begin{aligned}
& \mid-n-n \circ \sum_{\bar{d}}^{n} m m \in 0 \\
& \text { 8) } \\
& \text { ஸ़่ }
\end{aligned}
$$

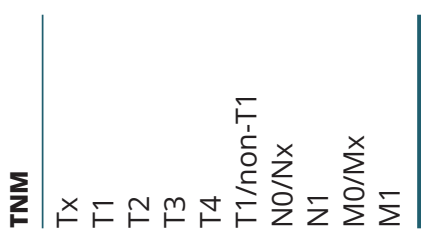

MTC in greater than $95 \%$ of mutation carriers. Since MTC is an aggressive disease that can eventually lead to death, early identification of asymptomatic carriers is essential, as it enables them to undergo prophylactic treatment by total thyroidectomy, increasing the chances of the disease being cured.

One interesting finding from the analysis of our data is that most of the literature presents the results of RET genotyping in relation to the number of families. However, as we have recently shown in studies of ancestry $(20,22)$, it is possible that many seemingly unrelated families actually present a common ancestor and thus would be considered one affected family, not several.

A correlation between genotypes and phenotypes was observed based on the analysis of the various mutations in the RET gene and their respective phenotypes. Age of onset and earliest age of lymph node metastases were factors taken into consideration to establish recommendations regarding the ideal time frame for prophylactic thyroidectomy. In addition, the prevalence of PHEO, primary hyperparathyroidism and their clinical presentation also served as a basis for current recommendations. In 2001, at the 7th International Workshop on MEN2 and MEN1, a guideline based on the indication for prophylactic thyroidectomy by the RET genotype (12) was proposed, which was followed by refinements resulting from new findings that demonstrated that prophylactic treatment was in fact justified, since it was associated with cure of the disease. These recommendations evolved into the guidelines of the ATA and other endocrine societies $(2,3,15,16)$.

However, with the increasing number of reports in terms of number of patients and geographies studied, some heterogeneity between the phenotypes of different families with the same RET mutation has been observed $(2,23,37)$. This heterogeneity justifies the need for a global effort to describe families with MEN2 to clarify the genetic or environmental circumstances that would modify these phenotypes.

This study presents some of the largest data ever collected, with genetic screening leading to the characterization of 554 patients with hereditary MTC. Unlike other studies, we were able to determine the etiology of the RET mutation in all patients with MEN2. One explanation may be the execution of an extensive technique for genotyping that was not restricted to the exons where the most common mutations occur (hot spots) $(29,38)$. Another interesting finding is that the systematic execution of RET genotyping in all patients with sporadic MTC allowed the identification of MEN2

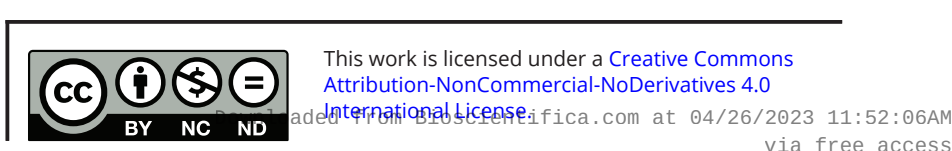


in several families of patients that initially presented with apparently sporadic disease.

We were concerned about the older age of diagnosis in this Brazilian cohort, a factor that contributes to a greater morbidity of the disease. This can be partly explained by a lower awareness of the typical physical findings observed in MEN2B carriers among general pediatricians and endocrinologists $(4,39)$. Another concerning observation was the size of the lesions with a high frequency of non-T1 tumors and the number of patients with distant metastases at initial presentation, suggesting poor access to health services and/or lower educational level, which affect early recognition of a health problem. On the other hand, we observed children carrying mutations in codons 611,618 , 620 (exon 10) and 630 (exon 11), which are considered of moderate risk in the ATA classification system, who were affected by MTC as early as 8 and 10 years old; this observation is in line with recent data demonstrating that early onset of disease should be considered as a predictor for tumor aggressiveness (40).

The comparison of the BrasMEN results with some of the largest published series in the literature $(5,18,36)$
- from Italy, Germany and France - showed similarities as well as differences (Table 3). While many mutations presented a similar prevalence, G533C and M918V were found mainly in Brazil. The M918T mutation, associated with MEN2B, was clearly more frequent in Brazil and Germany. Additionally, the most frequent mutation in codon C634 was C634Y.

The analysis of our data demonstrates a few peculiarities regarding RET mutations in Brazil. The first of these, based on the number of affected individuals, is the G533C mutation $(41,42)$. This family was originally from Barcelona, Spain and had migrated to the southeastern region of Brazil at the end of the nineteenth century. In our first description of the family, we mentioned that it would be plausible that individuals living in other countries could carry this mutation (41), since the Mediterranean Sea has always been a site of numerous migratory currents (42). Interestingly, as mentioned previously, some years later, Greek researchers described G533C as the most prevalent RET mutation in Greece $(43,44,45,46,47)$; this mutation was also described in a family with Greek ancestors living in the United States (48) and in a patient living in Ireland

Table 3 Comparison between mutation frequencies observed in BrasMEN and in 3 major published studies, Italy (18), Germany (5), and France (36).

\begin{tabular}{|c|c|c|c|c|c|c|c|c|c|}
\hline \multirow[b]{2}{*}{ RET codon } & \multicolumn{3}{|c|}{ BrasMEN } & \multicolumn{2}{|c|}{ Italy } & \multicolumn{2}{|c|}{ Germany } & \multicolumn{2}{|c|}{ France } \\
\hline & Families $(n)$ & $\%$ & MTC cases $(n)$ & Families $(n)$ & $\%$ & Families $(n)$ & $\%$ & Families $(n)$ & $\%$ \\
\hline T338 & 0 & 0 & 0 & 1 & 0.4 & 0 & 0 & 0 & 0 \\
\hline C515 & 0 & 0 & 0 & 1 & 0.4 & 0 & 0 & 2 & 0.5 \\
\hline dup531 & 0 & 0 & 0 & 0 & 0 & 0 & 0 & 1 & 0.2 \\
\hline G533 & 1 & 0.6 & 59 & 0 & 0 & 0 & 0 & 3 & 0.7 \\
\hline K603 & 0 & 0 & 0 & 0 & 0 & 0 & 0 & 1 & 0.2 \\
\hline C609 & 7 & 4.0 & 12 & 6 & 2.4 & 1 & 0.5 & 5 & 1.1 \\
\hline C611 & 6 & 3.4 & 12 & 1 & 0.4 & 6 & 3.1 & 12 & 2.7 \\
\hline C618 & 6 & 3.4 & 11 & 15 & 6.1 & 11 & 5.8 & 29 & 6.5 \\
\hline C620 & 6 & 3.4 & 56 & 9 & 3.7 & 14 & 7.3 & 31 & 7.0 \\
\hline C630 & 1 & 0.6 & 2 & 4 & 1.6 & 1 & 0.5 & 1 & 0.2 \\
\hline N631 & 0 & 0 & 0 & 0 & 0 & 0 & 0 & 0 & 0 \\
\hline C634 & 76 & 43.2 & 262 & 86 & 35.1 & 73 & 38.2 & 144 & 32.4 \\
\hline S649 & 0 & 0 & 0 & 0 & 0 & 0 & 0 & 2 & 0.5 \\
\hline K666 & 0 & 0 & 0 & 1 & 0.4 & 0 & 0 & 7 & 1.6 \\
\hline E768 & 6 & 3.4 & 14 & 9 & 3.7 & 2 & 1.0 & 14 & 3.2 \\
\hline L790 & 3 & 1.7 & 4 & 8 & 3.3 & 26 & 13.6 & 43 & 9.7 \\
\hline V804 & 23 & 12.5 & 46 & 52 & 21.2 & 19 & 9.9 & 95 & 21.4 \\
\hline M848 & 0 & 0 & 0 & 1 & 0.4 & 0 & 0 & 0 & 0 \\
\hline A883 & 0 & 0 & 0 & 1 & 0.4 & 0 & 0 & 3 & 0.7 \\
\hline S891 & 8 & 4.5 & 23 & 23 & 9.4 & 6 & 3.1 & 20 & 4.5 \\
\hline S904 & 0 & 0 & 0 & 1 & 0.4 & 0 & 0 & 0 & 0 \\
\hline R912 & 0 & 0 & 0 & 0 & 0 & 0 & 0 & 1 & 0.2 \\
\hline M918T & 26 & 14.8 & 32 & 20 & 8.2 & 32 & 16.8 & 29 & 6.5 \\
\hline M918V & 8 & 4.5 & 21 & 0 & 0 & 0 & 0 & 1 & 0.2 \\
\hline No mutations & 0 & 0 & 0 & 6 & 2.4 & 0 & 0 & 0 & 0 \\
\hline Total & 176 & 100 & 554 & 245 & 100 & 191 & 100 & 444 & 100 \\
\hline
\end{tabular}

All variants of unknown significance (VUS) have been excluded, including Y791F, now considered as non-pathogenic (34).

https://ec.bioscientifica.com https://doi.org/10.1530/EC-18-0506 (c) 2019 The authors Published by Bioscientifica Ltd

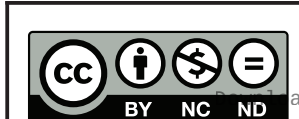

This work is licensed under a Creative Commons Attribution-NonCommercial-NoDerivatives 4.0 Internationab ticense.ifica com at $04 / 26 / 2023$ 11:52:06AM 
who was from Slovenia, another Mediterranean country (49). In view of these findings, we speculate that these families could have a common ancestor, as there have been several Greek city-states scattered throughout the Mediterranean since ancient times, including the Iberian Peninsula, where Barcelona is located (42). We confirmed this hypothesis by demonstrating that Brazilian patients (via Barcelona) and Greek patients have a common ancestor (22), a fascinating finding that suggests that, historically, the most plausible explanation for the origin of this mutation is that it occurred first in Greece and that the Greek migratory currents have taken it to the Iberian Peninsula; the fact that G533C is the most prevalent mutation in Greece reinforces this hypothesis.

Another important finding of our series was the discovery of the M918V mutation in the state of Ceará (20). Codon 918 is classically related to MEN2B and has been extensively studied since 1994, when the first mutation represented by a methionine substitution by threonine (M918T) was described $(9,10,11)$. Subsequently, researchers demonstrated that, of all possible substitutions at codon 918, only the M918T mutation showed a high transforming activity (50). In our study, in view of the clinical presentation of MTC related to M918V and the results of previous in silico and in vitro analyses (51), it was suggested that this exchange should be considered a moderate-risk mutation $(2,20)$.

In our opinion, however, the most interesting finding of our research concerning the M918V mutation was the complete study of its founding effect and the age of the founder mutation. At first, we thought that they were isolated families, but the haplotype study showed that all these patients had a common ancestor, and through historical and mathematical studies we have confirmed the existence of a pioneer who emigrated from Braga, Portugal, to Brazil in 1700, corroborating our hypothesis that this mutation accompanied the population of this region for approximately 350-400 years and that these supposedly different families belong to a single family that has been fragmented over the centuries.

Investigations from our group also contributed to determining that RET Y791F-only does not indicate an increased MTC risk (34). In addition, we have shown that patients with MEN2 who were initially reported to be RET Y791F-only carriers were also found to harbor other associated disease-causing RET variants (C634Y in cis), leading to the disease. Importantly, this arrangement modifies completely the clinical situation, and patients with Y791F/C634Y should be treated accordingly to the recommendations to those carrying
RET 634 mutations, in which total thyroidectomy must be performed $(33,34,35)$.

The findings that the mutations in the RET gene in Brazil bear a certain resemblance to those of the European population but also have some differences, which is explained by data on the genomic ancestry of Brazilians, indicate a high ancestral variability and that each Brazilian has a singular and quite individual proportion of European, African and Amerindian ancestry in his/her mosaic genome $(24,25)$. In all Brazilian regions studied, European ancestry was predominant, with proportions ranging from $60.6 \%$ in the northeast to $77.7 \%$ in the south. According to Pena et al., the immigration of six million Europeans to Brazil in the 19th and 20th centuries is largely responsible for dissipating previous ancestry dissimilarities that reflect region-specific population stories (25).

Despite the high number of patients included in this study, it has some limitations, as we do not yet have a nationwide view of the characteristics of MEN2 mutations in Brazil, since the centers that contributed the most in this study are located in the south and southeast regions; we had a good volume of patients from the northeast region, but since they were all from only two states, our observations have some bias. It should be emphasized that we studied only patients with the diagnosis of MTC and we did not include asymptomatic carriers.

In conclusion, this study enabled a more comprehensive understanding of RET mutations and the MEN2 phenotype distribution and prevalence in Brazil. This is one of the largest cohorts of MEN2 patients, and it is the first and a unique study collecting data from the majority of Brazilian centers involved in the diagnosis and treatment of thyroid cancer.

\section{Declaration of interest}

The authors declare that there is no conflict of interest that could be perceived as prejudicing the impartiality of the research reported.

\section{Funding}

This study was supported by research grants from the Sao Paulo State Research Foundation (FAPESP), numbers 2006/60402-1, 2010/51547-1 2013/01476-9 and 2014/06570-6 to R M B M, M R D S, S P A T and J M C and by a Fleury Group Research Grant (12518) to UNIFESP, and by a research grant from the Programa de Apoio a Núcleos de Excelência (PRONEX) /Rio Grande do Sul Research Foundation (FAPERGS), 16/2551-0000482-2, to ALM. Barretos Cancer Hospital was a recipient of a FINEP-CT-INFRA (02/2010). S C L and M S A S were recipients of FAPESP fellowships (2009/50575-4, 2010/51546-5 and 2012/21942-1). S P A T was a recipient of CAPES Senior Scientist at Universidade Federal de São Paulo (2013-2016). J M C, E I P, A L C, L S W and A L M are recipients of a Brazilian Research Council (CNPq) Productivity Scholarship. 


\section{Author contribution statement}

Drs Maciel R, Camacho and Lindsey had full access to all the data in the study and take responsibility for the integrity of the data and the accuracy of the data analysis. Drs Maciel R, Camacho, Lindsey, Dias-da-Silva, Hoff, Toledo $S$ and Maia conceived and design the study. All authors contributed to the acquisition, analysis and interpretation of data. Dr Camacho contributed to statistical analysis. Drs Maciel R, Dias-da-Silva, Palmero, Maia, and Cerutti obtained funding. Drs Maciel R, Camacho, Jorge, Graf, Lindsey, Lourenço Jr, Palmero, Maciel L, Mazeto, Nogueira, Toledo R, Vaisman, Ward, Dias-daSilva, Cerutti, Hoff, Toledo $S$ and Maia critically revised the manuscript. All authors approved the final version of the manuscript.

\section{Acknowledgements}

The authors are thankful to the Coordination for the Improvement of Higher Education Personnel, Brazil-Ministry of Education (CAPES) for the support to our Post-Graduation Programs. The authors are also thankful to the surgeons who performed the surgeries in our patients. Also, the authors acknowledge all patients and relatives who kindly hosted our regional BrasMEN task force in the Brazilian states of Ceará and Espírito Santo.

\section{References}

1 Mulligan LM. RET revisited: expanding the oncogenic portfolio. Nature Reviews Cancer 201414 173-186. (https://doi.org/10.1038/ nrc3680)

2 Wells SA Jr, Asa SL, Dralle H, Elisei R, Evans DB, Gagel RF, Lee N, Machens A, Moley JF, Pacini F, et al. Revised American Thyroid Association guidelines for the management of medullary thyroid carcinoma. Thyroid 201525 567-610. (https://doi.org/10.1089/ thy.2014.0335)

3 Maia AL, Ceolin L \& Maciel RMB. Multiple endocrine neoplasia type 2. In Guide of Oncology. Rio de Janeiro, Brazil: Brazilian National Cancer Institute, 2016

4 Hoff AO, Neves LAC \& Maciel RMB. Multiple endocrine neoplasia. In Endocrinology, Principles and Practice, 2nd ed., ch. 77, pp 1275-1284. Eds MJA Saad, RMB Maciel \& BB Mendonça. São Paulo, Brazil: Atheneu, 2017

5 Machens A, Lorenz K, Sekulla C, Hoppner W, Frank-Raue K, Raue F \& Dralle H. Molecular epidemiology of multiple endocrine neoplasia 2: implications for RET screening in the new millennium. European Journal of Endocrinology 2013168 307-314. (https://doi.org/10.1530/ EJE-12-0919)

6 Opsahl EM, Brauckhoff M, Schlichting E, Helset K, Svartberg J, Brauckhoff K, Maehle L, Engebretsen LF, Sigstad E, Groholt KK, et al. A natiowide study of multiple endocrine neoplasia type $2 \mathrm{~A}$ in Norway: predictive and prognostic factors for the clinical course of medullary thyroid carcinoma. Thyroid 201626 1225-1238. (https:// doi.org/10.1089/thy.2015.0673)

7 Mulligan LM, Kwok JB, Healey CS, Elsdon MJ, Eng C, Gardner E, Love DR, Mole SE, Moore JK, Papi L, et al. Germ-line mutations of the RET proto-oncogene in multiple endocrine neoplasia type $2 \mathrm{~A}$. Nature 1993363 458-460. (https://doi.org/10.1038/363458a0)

8 Donis-Keller H, Dou S, Chi D, Carlson KM, Toshima K, Lairmore TC, Howe JR, Moley JF, Goodfellow P \& Wells SA. Mutations in the RET proto-oncogene are associated with MEN 2A and FMTC. Human Molecular Genetics 19932 851-856. (https://doi.org/10.1093/ $\mathrm{hmg} / 2.7 .851$ )

9 Carlson KM, Dou S, Chi D, Scavarda N, Toshima K, Jackson CE, Wells SA Jr, Goodfellow PJ \& Donis-Keller H. Single missense mutation in the tyrosine kinase catalytic domain of the RET protooncogene is associated with multiple endocrine neoplasia type 2B. PNAS 199491 1579-1583. (https://doi.org/10.1073/ pnas.91.4.1579).

10 Hofstra RM, Landsvater RM, Ceccherini I, Stulp RP, Stelwagen T, Luo Y, Pasini B, Höppener JW, van Amstel HK, Romeo G, et al. A mutation in the RET proto-oncogene associated with multiple endocrine neoplasia type $2 \mathrm{~B}$ and sporadic medullary thyroid carcinoma. Nature 1994367 375-376. (https://doi. org/10.1038/367375a0)

11 Eng C, Smith DP, Mulligan LM, Nagai MA, Healey CS, Ponder MA, Gardner E, Scheumann GF, Jackson CE \& Tunnacliffe A. Point mutation within the tyrosine kinase domain of the RET protooncogene in multiple endocrine neoplasia type $2 \mathrm{~B}$ and related sporadic tumours. Human Molecular Genetics 19943 237-241. (https://doi.org/10.1093/hmg/3.2.237)

12 Brandi ML, Gagel RF, Angeli A, Bilezikian JP, Beck-Peccoz P, Bordi C, Conte-Devolx B, Falchetti A, Gheri RG, Libroia A, et al. Guidelines for diagnosis and therapy of MEN type 1 and type 2. Journal of Clinical Endocrinology and Metabolism 200186 5658-5671. (https://doi. org/10.1210/jcem.86.12.8070)

13 Machens A, Lorenz K \& Dralle H. Individualization of lymph node dissection in RET carriers at risk for medullary thyroid cancer: value of pretherapeutic calcitonin levels. Annals of Surgery 2009250 305-310. (https://doi.org/10.1097/SLA.0b013e3181ae333f)

14 Elisei R, Romei C, Renzini G, Bottici V, Cosci B, Molinaro E, Agate L, Cappagli V, Miccoli P, Berti P, et al. The timing of total thyroidectomy in RET gene mutation carriers could be personalized and safely planned on the basis of serum calcitonin: 18 years experience at one single center. Journal of Clinical Endocrinology and Metabolism 201297 426-435. (https://doi.org/10.1210/jc.2011-2046)

15 American Thyroid Association Guidelines Task Force, Kloos RT, Eng C, Evans DB, Francis GL, Gagel RF, Gharib H, Moley JF, Pacini F, Ringel MD, et al. Medullary thyroid cancer: management guidelines of the American Thyroid Association. Thyroid 200919 565-612. (https://doi.org/10.1089/thy.2008.0403)

16 Maia AL, Siqueira DR, Kulcsar MA, Tincani AJ, Mazeto GM \& Maciel LM. Diagnosis, treatment, and follow-up of medullary thyroid carcinoma: recommendations by the Thyroid Department of the Brazilian Society of Endocrinology and Metabolism. Arquivos Brasileiros de Endocrinologia e Metabologia 201458 667-700. (https:// doi.org/10.1590/0004-2730000003427)

17 Nicolli-Sire P, Murat A, Rohmer V, Franc S, Chabrier G, Baldet L, Maes B, Savagner F, Giraud S, Bezieu S, et al. Familial medullary thyroid carcinoma with non-cysteine RET mutations: phenotypegenotype relationship in a large series of patients. Journal of Clinical Endocrinology and Metabolism 200186 3746-3753. (https://doi. org/10.1210/jcem.86.8.7767)

18 Romei C, Mariotti S, Fugazzola L, Taccaliti A, Pacini F, Opocher G, Mian C, Castellano M, Degli Uberti E, Ceccherini I, et al. Multiple endocrine neoplasia type 2 syndromes (MEN 2); results from the ItaMEN network analysis on the prevalence of different genotypes and phenotypes. European Journal of Endocrinology 2010163 301-308. (https://doi.org/10.1530/EJE-10-0333)

19 Romei C, Tacito A, Molinaro E, Agate L, Bottici V, Viola D, Matrone A, Biagini A, Casella F, Ciampi R, et al. Twenty years of lesson learning: how does the RET genetic screening test impact the clinical management of medullary thyroid cancer? Clinical Endocrinology 201582 892-899. (https://doi.org/10.1111/cen.12686)

20 Martins-Costa MC, Cunha LL, Lindsey SC, Camacho CP, Dotto RP, Furuzawa GK, Sousa MSA, Kasamatsu TS, Kunii IS, Martins MM, et al. M918V RET mutation causes familial medullary thyroid carcinoma: study of 8 affected kindreds. Endocrine-Related Cancer 201623 909-920. (https://doi.org/10.1530/ERC-16-0141)

21 Mathiesen JS, Kroustrup JP, Vestergaard P, Stochholm K, Poulsen PL, Rasmussen AK, Feldt-Rasmussen U, Gaustadness M, Orntoff TB, Hansen TO, et al. Distribution of RET mutations in multiple https://ec.bioscientifica.com https://doi.org/10.1530/EC-18-0506
(C) 2019 The authors Published by Bioscientifica Ltd
This work is licensed under a Creative Commons Attribution-NonCommercial-NoDerivatives 4.0 International License.ifica com at 04/26/2023 11:52:06 Am 
endocrine neoplasia 2 in Denmark 1994-2014: a natiowide study. Thyroid 201727 215-223. (https://doi.org/10.1089/thy.2016.0411)

22 Cunha LL, Lindsey SC, França MIC, Sarika L, Papathoma A, Kunii IS, Cerutti JM, Dias-da-Silva MR, Alevizaki M \& Maciel RMB. Evidence for the founder effect of RET533 as the common Greek and Brazilian ancestor spreading multiple endocrine neoplasia 2A. European Journal of Endocrinology 2017176 515-519. (https://doi.org/10.1530/EJE-161021)

23 Machens A, Lorenz K, Weber F \& Dralle H. Geographic epidemiology of medullary thyroid cancer families: unearthing European ancestral heritage. Endocrine-Related Cancer 201825 L27-L30. (https://doi. org/10.1530/ERC-17-0514)

24 Pena SDJ, Bastos-Rodrigues L, Oimenta JR \& Bydlowski SP. DNA tests probe the genomic ancestry of Brazilians. Brazilian Journal of Medical and Biological Research 200942 870-876. (https://doi.org/10.1590/ S0100-879X2009005000026)

25 Pena SDJ, Di Pietro G, Fuchsuber-Moraes M, Genro JP, Hutz MH, Kehdy Fde S, Kohlrausch F, Magno LAV, Montenegro RC, Moraes MO, et al. The genomic ancestry of individuals from different geographical regions of Brazil is more uniform than expected. PLoS ONE 20116 e17063. (https://doi.org/10.1371/journal.pone.0017063)

26 Castinetti F, Maia AL, Peczkowska M, Barontini M, Hasse-Lazar K, Links TP, Toledo RA, Dvorakova S, Mian C, Bugalho MJ, et al. The penetrance of MEN2 pheochromocytoma is not only determined by ret mutations. Endocrine-Related Cancer 201724 L63-L67. (https://doi. org/10.1530/ERC-17-0189)

27 Maciel RMB, Bim LV, Camacho CP \& Cerutti JM. Penetrance of phaechromocytoma in RET G533C carriers differs between South America and Europe. Endocrine-Related Cancer 201825 L49-L51. (https://doi.org/10.1530/ERC-17-0349)

28 Edge SB, Byrd DR, Compton CC, Fritz AG, Greene FL \& Trotti A (Eds). AJCC Cancer Staging Manual, 7th ed. New York, NY, USA: Springer, 2010.

29 Lindsey SC, Kunii IS, Germano-Neto F, Sittoni MY, Camacho CP, Valente FOF, Yang JH, Signorini PS, Delcelo R, Cerutti JM, et al. Extended RET gene analysis in patients with apparently sporadic medullary thyroid cancer: clinical benefits and cost. Hormones and Cancer 20123 181-186. (https://doi.org/10.1007/s12672-012-0109-7)

30 Siqueira DR, Romiti M, da Rocha AP, Ceolin L, Meotti C, Estivalet A, Puñales MK \& Maia AL. The RET polymorphic allele S836S is associated with early metastatic disease in patients with hereditary or sporadic medullary thyroid carcinoma. Endocrine-Related Cancer 2010 17 953-963. (https://doi.org/10.1677/ERC-09-0312)

31 Toledo RA, Wagner SM, Coutinho FL, Lourenço DM, Azevedo JA, Longuini VC, Reis MT, Siqueira SA, Lucon AM, Tavares MR, et al. High penetrance of pheochromocytoma associated with the novel C634Y/Y791F double germline mutation in the RET protooncogene. Journal of Clinical Endocrinology and Metabolism 201095 1318-1327. (https://doi.org/10.1210/jc.2009-1355).

32 Magalhães PK, Antonini SR, de Paula FJ, de Freitas LC \& Maciel LMZ Primary hyperparathyroisim as the first clinical manifestation of multiple endocrine neoplasia type $2 \mathrm{~A}$ in a 5-year-old child. Thyroid 201121 547-550. (https://doi.org/10.1089/thy.2010.0336)

33 Valente FOF, Dias-da-Silva MR, Camacho CP, Kunii IS, Tamanaha R, Maciel RMB \& Cerutti JM. Comprehensive analysis of RET gene should be performed in patients with MEN 2 syndrome and no apparent genotype-phenotype correlation: an appraisal of p.Y791F and p.C634Y RET mutations in five unrelated Brazilian families. Journal of Endocrinological Investigation 201336 975-981. (https://doi. org/10.3275/8997)

34 Toledo RA, Hatanaka R, Lourenço DM Jr, Lindsey SC, Camacho CP, Almeida M, Lima JV Jr, Sekiya T, Garralda E, Naslavsky MS, et al. Comprehensive assessment of the disputed RET Y791F variant shows no association with medullary thyroid carcinoma susceptibility. Endocrine-Related Cancer 201522 65-76. (https://doi.org/10.1530/ ERC-14-0491)
35 Toledo RA, Lourenço DM Jr, Camacho C, Lindsey S, Cerutti J, Maciel RMB, Toledo SPA. RET Y791F: alone or accompanied? Archives of Endocrinology and Metabolism 201559 476-477. (https://doi org/10.1590/2359-3997000000060)

36 Lebeault M, Pinson S, Guillaud-Bataille M, Gomenez-Roqueplo AP, Carrie A, Barbu V, Pigny P, Bezieu S, Rey JM, Delvincourt C, et al. Nationwide French study of RET variants detected from 2003 to 2013 suggests a possible influence of polymorphisms as modifiers. Thyroid 201727 1511-1522. (https://doi.org/10.1089/thy.2016.0399)

37 Long KL, Etzel C, Rich T, Hyde S, Perrier ND, Graham PH, Lee JE, $\mathrm{Hu}$ MI, Cote GJ, Gagel R, et al. All in the family? Analyzing the impact of family history in addition to genotype on medullary thyroid carcinoma aggressiveness in MEN2A patients. Familial Cancer 201716 283-289. (https://doi.org/10.1007/s10689-016-9948-7)

38 Cerutti JM \& Maciel RMB. An unusual genotype-phenotype correlation in MEN 2 patients: should screening for RET double germline mutations be performed to avoid misleading diagnosis and treatment? Clinical Endocrinology 201379 591-592. (https://doi. org/10.1111/cen.12155)

39 Camacho CP, Hoff AO, Lindsey SC, Signorini PS, Valente FOF, Oliveira MNL, Biscolla RPM, Cerutti JM \& Maciel RMB. Early diagnosis of multiple endocrine neoplasia type $2 \mathrm{~B}$ : a challenge for physicians. Archives of Endocrinology and Metabolism 200852 1393-1398. (https://doi.org/10.1590/S0004-27302008000800031)

40 Voss RK, Feng L, Lee JE, Perrier ND, Graham PH, Hyde SM, NievesMunoz F, Cabanillas ME, Waguspak SG, Cote GJ, et al. Medullary thyroid carcinoma in MEN2A: ATA moderate- or high-risk mutations do not predict disease aggressiveness. Journal of Clinical Endocrinology and Metabolism 2017102 2807-2813. (https://doi.org/10.1210/ jc.2017-00317)

41 Da Silva AM, Maciel RM, Da Silva MR, Toledo SR, De Carvalho MB \& Cerutti JM. A novel germ-line point mutation in RET exon 8 (Gly533Cys) in a large kindred with familial medullary thyroid carcinoma. Journal of Clinical Endocrinology and Metabolism $2013 \mathbf{8 8}$ 5438-5443. (https://doi.org/10.1210/jc.2003-030997)

42 Signorini PS, Franca MIC, Camacho CP, Lindsey SC, Valente FOF, Kasamatsu TS, Machado AL, Salim CP, Delcelo R, Hoff AO, et al. A ten-year clinical update of a large RET p.Gly533Cys kindred with medullary thyroid carcinoma emphasizes the need for an individualized assessment of affected relatives. Clinical Endocrinology 201480 235-245. (https://doi.org/10.1111/cen.12264)

43 Braudel F. The Mediterranean and the Mediterranean World in the Age of Philip II. Berkeley, CA, USA: University of California Press, 1995.

44 Kaldrymides P, Mytakidis N, Anagnostopoulos T, Vassilou M, Terpiti A, Zahariou M, Rampias T, Koutsodontis G, Konstantopoulou I, Ladopoulou A, et al. A rare RET gene exon 8 mutation is found in two Greek kindreds with familial medullary thyroid carcinoma implications for screening. Clinical Endocrinology 200664 561-566. (https://doi.org/10.1111/j.13652265.2006.02509.x)

45 Bethanis S, Koutsodontis G, Palouka T, Avgoustis C, Yannoukakos D, Bei T, Papadopoulos S, Linos D \& Tsagarakis S. A newly detected mutation of the RET protooncogene in exon 8 as a cause of multiple endocrine neoplasia type 2A. Hormones 20076 152-156. (https://doi. org/10.1530/ERC-17-0189)

46 Peppa M, Boutati E, Kamakari S, Pikounis V, Peros G, Panayiotides IG, Economopoulos T, Raptis SA \& Hadjidakis D. Multiple endocrine neoplasia type $2 \mathrm{~A}$ in two families with the familial medullary thyroid carcinoma associated G533C mutation of the RET proto-oncogene. European Journal of Endocrinology 2008159 767-771. (https://doi. org/10.1530/EJE-08-0476)

47 Sarika HL, Papathoma A, Garofalaki M, Vasileiou V, Vlassopoulou B, Anastasiou E \& Alevizaki M. High prevalence of exon 8 G533C mutation in apparently sporadic medullary thyroid carcinoma in Greece. Clinical Endocrinology 201277 857-862. (https://doi. org/10.1111/j.1365-2265.2012.04462.x) 
48 Sarika HL, Papathoma A, Garofalaki M, Saltiki K, Pappa T, Pazaitou-Panayiotou K, Anastasiou E \& Alevizaki M. Genetic screening of patients with medullary thyroid cancer in a referral center in Greece during the past two decades. European Journal of Endocrinology 2015172 501-509. (https://doi.org/10.1530/EJE-140817)

49 Castro MR, Thomas BC, Richards ML, Zhang J \& Morris JC. Multiple endocrine neoplasia type $2 \mathrm{~A}$ due to an exon 8 (G533C) mutation in a large North American kindred. Thyroid 201323 1547-1552. (https:// doi.org/ 10.1089/thy.2012.0599)

50 Casey R, Prendeville S, Joyce C \& O'Halloran D. First reported case in Ireland of MEN2A due to a rare mutation in exon 8 of the RET oncogene. Endocrinology, Diabetes and Metabolism Case Reports 2013 2013 130044. (https://doi.org/10.1530/EDM-13-0044)

51 Cirafici AM, Salvatore G, De Vita G, Carlomagno F, Dathan NA, Visconti R, Melillo RM, Fusco A \& Santoro M. Only the substitution of methionine 918 with a threonine and not with other residues activates RET transforming potential. Endocrinology 1997138 1450-1455. (https://doi.org/10.1210/endo.138.4.5073)

52 Cosci B, Vivaldi A, Romei C, Gemignani F, Landi S, Ciampi R, Tacito A, Molinaro E, Agate L, Bottici V, et al. In silico and in vitro analysis of rare germline allelic variants of RET oncogene associated with medullary thyroid cancer. Endocrine-Related Cancer 201118 603-612. (https://doi.org/10.1530/ERC-11-0117).

Received in final form 30 January 2019

Accepted 13 February 2019

Accepted Preprint published online 13 February 2019 (c) 2019 The authors Published by Bioscientifica Ltd
This work is licensed under a Creative Commons Attribution-NonCommercial-NoDerivatives 4.0 Internationad ticense ifica. com at 04/26/2023 11:52:06AM 